MISS MARIELA CECILIA BUSTOS (Orcid ID : 0000-0003-4444-065X)

DR. MARCELA L MARTINEZ (Orcid ID : 0000-0003-0249-7535)

Article type : Original Manuscript

\title{
STUDY OF THE INCORPORATION OF NATIVE AND MICROENCAPSULATED CHIA SEED OIL ON PASTA PROPERTIES
}

Pasta with encapsulated chia oil

\begin{abstract}
Agustín González ${ }^{(1,2)}$, María Gabriela Bordón ${ }^{(3,4)}$, Mariela C. Bustos ${ }^{(4)}$, Karina L. Córdova Salazar ${ }^{(3)}$, Pablo D. Ribotta ${ }^{(3,4)}$, Marcela L. Martínez ${ }^{(3,5)}$ *
\end{abstract}

(1) Instituto de Investigación y Desarrollo de Ingeniería de Procesos y Química Aplicada (IPQACONICET).

(2) Universidad Nacional de Córdoba. Facultad de Ciencias Químicas. Departamento de Química Orgánica. Córdoba, Argentina.

(3) Instituto de Ciencia y Tecnología de los Alimentos, Facultad de Ciencias Exactas, Físicas y Naturales (ICTA-FCEFyN) - Universidad Nacional de Córdoba.

(4) Instituto de Ciencia y Tecnología de los Alimentos Córdoba (ICYTAC-CONICET).

(5) Instituto Multidisciplinario de Biología Vegetal (IMBIV-CONICET).

*Corresponding author: Dr. Marcela L. Martinez

Adress: Av. Vélez Sarsfield 1611(5000), Córdoba, Argentina.

E-mail: marcela.martinez@unc.edu.ar or marcelamartinez78@hotmail.com

Tel: $+549-3516008547$

This article has been accepted for publication and undergone full peer review but has not been through the copyediting, typesetting, pagination and proofreading process, which may lead to differences between this version and the Version of Record. Please cite this article as doi: $\underline{10.1111 / \text { IJFS.14623 }}$

This article is protected by copyright. All rights reserved 


\section{ABSTRACT}

The present work studied the effect of the incorporation of encapsulated chia seed oil on the cooking quality of dry pasta. Pasta morphology and oil distribution in the samples were studied. No significant variations were determined in cooking parameters as optimal cooking time, cooking loss and texture of cooked pasta with the incorporation of the encapsulated oil, but significant differences were determined in uncooked pasta texture and variables that describe water interaction, such as water absorption and swelling index. In addition, the incorporation of microencapsulated oil avoided oxidative deterioration, showing a protective effect and preventing the formation of hydroperoxide radicals in pasta preparation, storage and cooking procedures (compared with free oil-containing pasta), resulting in a safer product. Storage at modified atmosphere exerts an additional protective effect on oil, enhancing the effect of the microcapsules. Microencapsulation proved to be an effective technology that preserves oil quality in $\omega-3$ rich pasta.

KEYWORDS: dry pasta; $\omega-3$; chia oil; cooking quality; oil stability.

This article is protected by copyright. All rights reserved 


\section{INTRODUCTION}

Durum wheat pasta, a traditional and extensively accepted food due to its nutritional and sensory properties, is recognized as a good transport to deliver healthy ingredients given its easy processing and cooking, low cost and extended shelf-life (Brennan et al. 2004).

A polyunsaturated fatty acid (PUFA)-rich diet reduces the risk of developing cancer, cardiovascular diseases, and metabolic syndrome (Galli and Marangoni 2006). The International Society for the Study of Fatty Acids and Lipids (ISSFAL) suggests a daily intake of $1 \mathrm{~g} \omega$-3 fatty acids/ day (a-linolenic acid) (Hermida and Gallardo 2015).

Chia seed (Salvia hispanica L.) oil is mainly characterized by the high amounts of $\omega-3$ fatty acids (61-70\%) (Martinez et al. 2012). Several studies on food enrichment have been reported, including chocolate milk (Morato et al. 2015), bread (González et al. 2018), or Indian yogurt (Goyal et al. 2016) fortified with $\omega-3$ fatty acids. Some reports about $\omega-3$ fatty acid enrichment of pasta can be found in the literature. Studies include the incorporation of microalgae (Rodríguez De Marco et al. 2018), $\omega-3$ fatty acid extract from fish (Filipovićet al. 2015), or flaxseed oils (Villeneuve et al. 2013). However, in none of these studies, the active component ( $\omega-3$ fatty acids) is protected, showing a marked deterioration when consumed. The incorporation of PUFAs in food may be restricted due to their susceptibility to oxidative reactions mainly in the processing and storage of pasta, deteriorating their chemical and organoleptic quality. A technology capable of protecting the active compounds, that prevents oil oxidation and maintains its nutritional characteristics is microencapsulation. In a previous work (González et al. 2016) we studied chia oil protection, observing that microencapsulation through freeze-drying using soy protein isolate as wall material exerts a protective effect on chia oil. The oxidative stability index values (OSI) of microencapsulated oils under accelerated oxidative conditions were 2-fold higher than those of non-encapsulated oil. Moreover, the hydroperoxide values for microencapsulated oil stored under $25{ }^{\circ} \mathrm{C}$ for 90 days were lower than the recommended limit for virgin and cold-pressed vegetable oils (15 meq. $\mathrm{O}_{2} / \mathrm{kg}$ oil) established by Codex (Codex Alimentarius 2001), whereas the nonencapsulated chia oil reached the above limit in 62 days. These results suggest an enhancement of the oil shelf-life up to $30-48 \%$.

Accordingly, the development of $\omega$-3-rich dried pasta responds to a major challenge given that it requires processing conditions at high temperature and at relatively long storage time (Hermida and Gallardo 2015).Taking into account the lack of scientific information on the incorporation of microencapsulated chia oil into dry pasta, the present work attempts to analyze the effects of non-encapsulated and encapsulated chia seed oil on dry pasta and on oil quality after pasta production, cooking and storage. 


\section{MATERIALS AND METHODS}

\section{Materials}

Bread wheat flour without additives (Industrias Alimenticias Tiranti S.R.L, Argentina) was employed. The flour presented a moisture, protein, lipid and ash contents of $13.10 \pm 0.03,12.08 \pm$ $0.07,0.9 \pm 0.2$, and $0.42 \pm 0.02 \%$ (dry basis), respectively. Gluten index, wet, and dry gluten were $98.9 \pm 0.5 ; 20.7 \pm 0.5$, and $7.8 \pm 0.2 \mathrm{~g} / 100 \mathrm{~g}$, respectively. Also, sodium chloride $(\mathrm{NaCl})$, soy protein isolate (SPI) SUPRO E ( $90 \%$ protein content, dry basis) (Tecnoalimenti, Argentina) were used. Chia seed oil (CSO) was produced by cold-pressing. The solvents and reagents used were HPLC or analytical grade.

\section{Elaboration of chia seed oil-containing microcapsules}

Chia oil was extracted from seeds with $10 \%(\mathrm{w} / \mathrm{w})$ of moisture content by compression at $30{ }^{\circ} \mathrm{C}$ using a screw press (Komet CA 59G; IBG Monforts, Mönchengladbach, Germany). Chemical quality of the obtained oil was studied measuring acid index (Al), conjugated trienes (K270) and dienes (K232) following the AOCS (2009) methodology, and oxidative stability indexes (OSI) determined by Rancimat equipment where the heating block temperature and the air flow rate were set at $110^{\circ} \mathrm{C}$ and $20 \mathrm{~L} / \mathrm{h}$, respectively (Gallardo et al. 2013).

CSO-containing microcapsules with SPI as wall material were produced as described previously (González et al. 2016). In brief, SPI dispersion (8\%, w/v on a dry basis) was prepared; the $\mathrm{pH}$ was adjusted to 7.0 and maintained all night at $4{ }^{\circ} \mathrm{C}$. CSO was added drop by drop into the dispersions in a 2:1 ratio (SPI:oil) while dispersions were stirred at $18000 \mathrm{rpm}$ with an Ultraturrax homogenizer (IKA - T18, Staufen, Germany). A laboratory bench-top freeze-dryer (L-T8; Rificor, Buenos Aires, Argentina) that works with a condenser at $-50{ }^{\circ} \mathrm{C}$ and a vacuum of $10 \mathrm{~Pa}$ was used to dry the emulsions during $36 \mathrm{~h}$. Total and superficial oil content, encapsulation efficiency, oil hydroperoxide value and oxidative stability index were determined for microcapsules according to González et al. (2016).

\section{Pasta-making procedure}

Pasta samples were produced according to Bustos, Perez and León (2011) formulation. One hundred and fifty $\mathrm{g}$ of flour, $1,5 \mathrm{~g}$ of $\mathrm{NaCl}$ and distilled water (added until a final moisture of 35$40 \%$ was reached) were mixed in a pilot scale extruder (Monferrina DOLLY Pasta Extruder, Italy) during $10 \mathrm{~min}$ in order to obtain a uniform hydration of flour particles. The dough was then extruded (pasta final temperature did not exceed $45-50^{\circ} \mathrm{C}$ ) through a die to get a tagliatelle form (thickness of $2.1 \pm 0.2 \mathrm{~mm}$, length of $250 \pm 30 \mathrm{~mm}$ and width of $8 \pm 1 \mathrm{~mm}$ ). The product was dried at $45{ }^{\circ} \mathrm{C}$ in humidity-controlled dryer chamber (75\%) (FAC CDH4060, Argentina) during $17.5 \mathrm{~h}$ until 
a final moisture content lower than $12 \%$. Pasta samples were packaged in clean film and saved in closed containers at $25^{\circ} \mathrm{C}$ until required. Three batches for each pasta type were produced.

\section{Dry pasta formulations (DPF)}

Three mandatory values were taking into account for the formulation of omega-3 fortified pasta: i) the recommended daily ingestion of $\omega-3$ fatty acids ( $1 \mathrm{~g} /$ day) according to the International Society for the Study of Fatty Acids and Lipids (ISSFAL) (Hermida and Gallardo 2015); ii) the content of $\omega-3$ fatty acid in chia oil $(0.6 \mathrm{~g} / \mathrm{g}$ of oil); and iii) the total oil content in $1 \mathrm{~g}$ of microcapsules $(\mathrm{MC})$ obtained by freeze-drying $(0.33 \mathrm{~g})$. From these, the following formulations were prepared:

- Pasta+MC: dry pasta containing the amount of MC necessary to satisfy, in a $100 \mathrm{~g}$ portion of product, $100 \%$ of the suggested intake value per day of $\omega-3$ for a healthy adult $(5.85 \mathrm{~g}$ of MC/100 $g$ of flour).

- Pasta+oil: dry pasta with the addition of non-encapsulated oil (bulk oil) and SPI both in the same amount with respect to that contained in the MC incorporated to Pasta+MC formulation (1.93 $\mathrm{g}$ of oil / $100 \mathrm{~g}$ of flour).

- Control pasta: dry Control pasta without the addition of oil, replacing the amount of MC or SPI by wheat flour.

\section{Evaluation of cooking properties}

Four $\mathrm{g}$ of dried pasta were cut into $5 \mathrm{~cm}$ long pieces and cooked in $200 \mathrm{~mL}$ of boiling distilled water until reaching its optimum cooking time. After draining, the samples were studied through methodologies that describe pasta quality as was documented by Bustos et al. (2011) and Martinez et al. (2017). Each determination was carried out in triplicate.

\section{Optimal cooking time (OCT)}

The "al dente" point was established by compressing the pasta sample of $5 \mathrm{~cm}$ between two glass slides every $30 \mathrm{~s}$. The OCT was achieved when the white center, which represents the ungelatinized starch, had just disappeared as stated by AACC (2000).

\section{Cooking loss (CL)}

The water collected from each OCT assay was evaporated at $105{ }^{\circ} \mathrm{C}$ until reaching constant weight. The remnant was weighed and reported as percentage of initial sample in concordance with AACC (2000).

\section{Water absorption (WA)}

$12.5 \mathrm{~g}$ of pasta samples were broken into pieces of $5 \mathrm{~cm}$ which were cooked in boiling water (200 $\mathrm{mL}$ ) up to reaching its OCT. Then, the cooked pasta was drained and washed with clean water 
$(50 \mathrm{~mL})$ at $25^{\circ} \mathrm{C}$ for $1 \mathrm{~min}$. Finally, they were weighed after attaining room temperature. WA of pasta was calculated as follows:
$\mathrm{WA}=\left[\left(W_{c p}-\mathrm{W}_{\text {ucp }}\right) / \mathrm{W}_{\text {ucp }}\right] \times 100$.
Equation 1.

Where $W_{c p}$ is weight of cooked pasta and $W_{u c p}$ is weight of uncooked pasta.

\section{Swelling Index (SI)}

Cooked pasta swelling index ( $\mathrm{g}$ of water per $\mathrm{g}$ of dry pasta) was determined by drying cooked pasta samples at $105^{\circ} \mathrm{C}$ up to constant weight and calculated as follows:
$\mathrm{SI}=\left[\left(W_{c p}-W_{\mathrm{dcp}}\right) / \mathrm{W}_{\mathrm{dcp}}\right] \times 100$
Equation 2.

Where $W_{c p}$ is weight of cooked pasta and $W_{d c p}$ is weight of dried cooked pasta.

\section{Pasta texture}

Texture of uncooked and cooked pasta was analyzed using a Universal Testing Machine (Model 3342, Instron, EUA) equipped with a $50 \mathrm{~N}$ cell. A probe of the HDP / 3PB (three-point bending) type was used to exert a compressive force on the uncooked pasta $(5 \mathrm{~cm})$ until breaking. The breaking force expressed as the maximum force required for the fracture was obtained. Firmness and adhesiveness of cooked pasta were determined using a AP/35 cylinder probe and force was measured in compression mode fixed at $50 \%$ of strain (Aranibar et al. 2018). The displacement speed was $0.2 \mathrm{~mm} / \mathrm{s}$ for all assays.

\section{Microstructure of dry and cooked pasta}

The pasta morphology was analyzed by scanning electron microscopy (Carl Zeiss -Sigma, Germany) and confocal fluorescence microscopy (LSM5 Pascal; Zeiss, Oberkochen, Germany). Oil distribution was visualized by staining dry pasta sample with Nile Red (Sigma-Aldrich, St Louis, MO, USA) (1 g / kg fat basis). The excitation was done using a 488nm argon-ion laser and detection through a 515/30 filter (González et al. 2018). To study the microstructure by scanning electron microscopy a gold coat was applied on the freeze-dried samples.

\section{Oil chemical quality}

In order to extract the contained oil, dry pasta was cut in small pieces and put in contact with hexane overnight at $4{ }^{\circ} \mathrm{C}$. Cooked pasta was previously freeze-dried before oil extraction.

\section{Hydroperoxide value (HPV) determination}

HPV of the oil obtained from the dry and cooked Control pasta, Pasta+oil and Pasta+MC samples, was measured in triplicate. HPV was determined by iodometric titration, according to AOCS (2009) methodology, after extraction of the oil from dry and cooked pasta with n-hexane during $24 \mathrm{~h}$ at $25^{\circ} \mathrm{C}$.

\section{Fatty acid composition (FAC)}

FAC of oil samples was studied with a gas chromatograph (Perkin Elmer, Shelton, CT, USA) following the methodology used by Martínez et al. (2006). In order to quantify every fatty acid an 
internal standard (henicosanoic acid, Sigma-Aldrich) was used. Each determination was done in triplicate.

\section{Storage stability test}

Control pasta, Pasta+oil and Pasta+MC samples were stored in bags (metalized oriented polypropylene, OPP) film with an oxygen transmission rate of $19 \mathrm{cc} / \mathrm{m}^{2} / 24 \mathrm{~h}$ and a water vapor transmission of $155 \mathrm{~g} / \mathrm{m}^{2} / 24 \mathrm{~h}$ determined at $23{ }^{\circ} \mathrm{C}-0 \% \mathrm{RH}$ and $38{ }^{\circ} \mathrm{C}-90 \% \mathrm{RH}$, respectively) with a) modified atmosphere (nitrogen) and b) no modified atmosphere (air). The bags were put in a thermostated compartment at $25 \pm 1{ }^{\circ} \mathrm{C}$ during 90 days. Samples were taken every 30 days and HPV was evaluated.

\section{Statistical study}

An ANOVA test at $5 \%$ level $(p<0.05)$ of significance was used to estimate statistical differences among treatments for all parameters. When a significant difference was found, a pair wise comparison of mean by Fisher LSD was done.

\section{RESULTS AND DISCUSSION}

Cold-pressed chia oil was characterized measuring HPV, fatty acid profile, AI, OSI and K232 and K270 (Table 1), showing an optimal chemical quality as reported by Martinez et al. (2012).The microencapsulated chia oil showed a whitish powder aspect. The chemical quality of the microencapsulated oil did not show significant differences $(p<0.05)$ in HPV $\left(0.42 \pm 0.02 \mathrm{meq} \mathrm{O}_{2} / \mathrm{kg}\right.$ oil), compared with the cold-pressed chia oil. Microcapsules showed moisture content, total oil and encapsulation efficiency values of $3.86 \pm 0.02 \%$ (b.w.); $0.34 \pm 0.02 \mathrm{~g} / \mathrm{g}$ solids and $55.1 \pm 3.9 \%$, respectively, in accordance with those reported by González et al. (2016).

Bulk and microcapsulated CSO were incorporated as ingredients to pasta formulation to produce $\omega-3$ fortified product.

\section{Evaluation of cooking quality of pasta}

Since pasta behavior during and after cooking is of particular importance for consumers and food industry, some product properties were determined in order to know whether the incorporation of $\mathrm{MC}$ or free oil affected pasta quality.

OCT was $6.00 \mathrm{~min}$ for all samples and was not affected by MC or free oil incorporation, this value being optimal for dry pasta. CL, one of the main variables to predict the overall cooking performance of pasta showed values between 5.28-5.6g/100gt dry pasta, showing no significant differences among the samples (Table 2). According to these results, the $\omega-3$ fortified pasta can be considered of good quality since $C L$ did not go beyond the accepted values for durum wheat pasta (below 8\%; Dick and Youngs 1988). 
WA varied between 137.15 and $167.58 \%$, and Pasta+MC and Pasta+oil samples (Table 2) showed significantly lower WA values $(p<0.05)$ than Control pasta. These results showed that water absorbed by proteins and starch during cooking was different in pasta fortified with $\omega-3$ fatty acids. The lower WA percentages obtained for Pasta+MC and Pasta+oil samples may be due the presence of SPI, which could control water distribution, reducing its availability for starch gelatinization during cooking (Sozer 2009). Moreover, the effect of WA reduction in pasta with greater amount of oil is known, given that oil forms complexes with amylose (Badui 2006). Similar trends were observed for SI values, where the highest value, $2.12 \mathrm{~g}$ of water / $\mathrm{g}$ of dry pasta, corresponded to Control pasta. The decrease in SI for the pasta could be attributed to the protein network formed that limits starch swelling. During cooking, proteins, and starch strongly compete for water since protein denaturation begins at approximately the same temperature as the starch gelatinization. Proteins require water to coagulate and form a network, as starch absorbs it, swells, gelatinizes and tends to solubilize (Martínez 2010). This effect produces a decrease in water availability for starch reflecting a lower SI.

Pasta texture is one of the characteristics that determine the final approval by consumers. Dry pasta analysis demonstrated that the breaking force of uncooked pasta is affected by product composition. Indeed, Pasta+MC and Pasta+oil showed a significantly lower resistance to fracture than Control pasta (Table 3). The surface oil portion produces a lubricant effect through the pasta matrix due to its well-known role as a softener. In addition, the oil content seemed to affect the dry product structure, therefore reducing uncooked pasta breaking force. A different behavior was observed for cooked pasta, for which the firmness and adhesiveness were not significantly different among pasta samples (Table 3). These results are in concordance with Aranibar et al. (2018) who studied the effect of the incorporation of a partially-deoiled chia flour in wheat pasta formulation. The authors observed a statistically significant decrease in firmness while the percentage of the partially-deolied chia flour increased in uncooked samples, but all cooked pasta samples showed a similar texture performance. The results obtained in the present study suggest that the incorporation of this amount of microencapsulated or free oil in the product would not seem to affect the textural properties of cooked pasta.

The microstructure of starch-protein matrix in MC and oil-containing pasta was analyzed by SEM (Figure 1). Dry pasta samples showed type A and B starch granules (point 1 and 2 in Figure 1, respectively) of 10 to $20 \mu \mathrm{m}$ and 3 to $5 \mu \mathrm{m}$-size, respectively, revealing no apparent differences between the three-pasta prepared. It should be noted that in pasta with MC, these structures could not be visibly observed, as their shape and size are similar to those of type $B$ starch granules. Yet, it is possible to see an increase in the number of these structures, some of them with no spherical shape, probably attributed to the presence of oil microcapsules. On the other 
hand, in cooked pasta, difference between samples could not be found. Nevertheless, cooked pasta showed smooth surfaces over the matrix compared with dry pasta (point 3 in Figure 1), due to the presence of swollen starch granules that turn them less noticeable. Moreover, in cooked pasta, porous regions could be observed (point 4 in Figure 1), possibly ascribed to the release of starch granules during cooking.

In order to differentiate MC from type B starch granules, a confocal microscopy with fluorescence analysis was made (Figure 2) using Nile Red to stain the lipid phase. Dry Control pasta presented small amounts of lipid from the wheat flour included in the matrix. Regarding dry and cooked pasta with non-encapsulated oil, a heterogeneous distribution of the lipid phase forming amorphous structures of important size was observed. Finally, in dry and cooked pasta with MC, oil was distributed in the matrix in small drops, forming part of microcapsules. This could be evidenced by overlapping confocal and optical images. On the other hand, the cooked sample showed a small amount of free oil possibly released from MC during cooking. These results were similar to those observed by Gallardo et al. (2013) in bread fortified with microencapsulated flaxseed oil.

\section{Study of oil stability}

In order to study the stability of the oils contained in dry and cooked samples (Pasta+MC and Pasta+oil), HPV was determined (Table 4). A very low HPV was determined in dry pasta with microencapsulated CSO, which suggests that there is no oxidation of the oil produced by the microencapsulation process and pasta preparation. Actually, no differences in HPV was found between oil obtained from dry Pasta+MC samples and control oil (optimal quality oil). On the contrary, oil extracted from dry Pasta+oil samples showed a significantly greater HPV than that in the oil obtained from Pasta+MC samples. As can be seen for Pasta+oil samples, HPV increased due to pasta preparation, in contrast to Pasta+MC where no changes were determined. This oxidation observed for Pasta+oil samples is derived in part from the fact that the pasta making process, when it is not conducted under vacuum, allows the incorporation of oxygen molecules that trigger lipid oxidation (Borrelli et al. 2003). Cooking procedure increased HPV of both pasta samples, however, a markedly larger difference was determined between cooked and uncooked pasta for Pasta +oil compared with Pasta+MC samples.

From the comparison of the HPV determined for both samples (Pasta+MC and Pasta+oil) it could be observed that microcapsule wall exerts a protective effect against pasta manufacturing and cooking conditions. The oil contained in cooked Pasta+oil showed the greatest generation of primary oxidation compounds. Verardo et al. (2009) studied lipid oxidative stability in spaghetti fortified with polyunsaturated fatty acids from marine origin and reported that pasta process 
conditions negatively affected oil chemical stability. Similar trends were reported by González et al. (2018) in bread with $\omega-3$ fatty acids from chia oil.

\section{Storage stability test}

Different lots of the different pasta samples were stored under air (unmodified atmosphere) and under $\mathrm{N}_{2}$ (modified atmosphere). Since traditional dry pasta constitutes food with a prolonged shelf-life, modified atmosphere represents an antioxidant physical barrier to lipid oxidation given that the developed pasta contains polyunsaturated oil. The results showed that all values measured are lower than the Codex acceptance limit for cold-pressed and virgin vegetable oils (15 milliequivalents of $\mathrm{O}_{2} / \mathrm{kg}$ oil) (Codex alimentarius 2001), derived from a protective effect of the pasta matrix on oil. Considering the entire storage stability test, a noticeable protective effect provided by the microcapsule walls and the modified atmosphere was observed. The Pasta+MC sample packaged in modified atmosphere showed the highest oxidative stability, with a HPV of $2.34 \pm 0.11 \mathrm{meq}_{2} / \mathrm{kg}$ oil (Figure 3 ) at day 150. Pasta+oil sample packed without modified atmosphere showed the lowest oxidative stability $\left(6.34 \pm 0.18 \mathrm{meq} \mathrm{O}_{2} / \mathrm{kgoil}\right)$. A protective effect produced by microencapsulation could be clearly seen, since a lower HPV was determined for both storage atmospheres. On the other hand, results show that the modified atmosphere exerts an additional protective effect on lipid stability, enhancing the protecting effect of the MC wall material.

\section{CONCLUSIONS}

The inclusion of microencapsulated chia seed oil did not modify some variables that describe the pasta cooking quality, such as optimal cooking time and cooking loss, and textural properties (firmness and adhesiveness) of cooked pasta; nonetheless, it produced variations in the breaking force of the dry pasta and in variables related to water interaction (water absorption and swelling index). In addition, the encapsulation of the incorporated chia seed oil presented a protective effect delaying oil oxidation, preventing the generation of primary oxidation products such as hydroperoxides radicals. The protective effect given by microencapsulation could be determined in each important step, such as pasta preparation, storage until 150 days and cooking for consumption. The modified atmosphere provides an additional preservation of the lipid matrix, enhancing the protective effect of the MC wall material. The microencapsulation of chia oil proved to be a procedure that allows developing $\omega-3$ fortified food such as dry pasta.

\section{ACKNOWLEDGEMENTS}


The authors acknowledge financial support from CONICET (PIP-11220120100184), Fondo para

la InvestigaciónCientífica y Tecnológica (FONCyT, BID PICT 2014-2283), Project CYTED Program 119RT0567 and SeCyT-UNC (05/M287 and 411/18).

\section{CONFLICTS OF INTEREST}

Ethics approval was not required for this research.

\section{DATA AVAILABILITY STATEMENT}

The data that support the findings of this study are available from the authors upon reasonable request.

\section{REFERENCES}

AACC American Association of Cereal Chemistry (2000). Approved methods of the American Association of Cereal Chemists, 9th Ed. St. Paul, MN, USA: American Association of Cereal Chemists.

AOCS (2009). Official methods and recommended practices of the AOCS. Champaign, USA. Aranibar, C., Pigni, N.B., Martinez, M., Aguirre, A., Ribotta, P.D., Wunderlin, D., Borneo, R. (2018). Utilization of a partially-deoiled chia flour to improve the nutritional and antioxidant properties of wheat pasta. LWT - Food Science and Technology, 89, 381-387.

This report is important in our manuscript because an interesting comparison can be performed between the products. In addition, similar tests were carried out, particularly those related to textural properties.

Badui, D.S.(2006). Química de los alimentos. México: Pearson Educación de México.

Borrelli, G.M., De Leonardis, A.M., Fares, C., Platani, C., Di Fonzo, N. (2003). Effects of modified processing conditions on oxidative properties of Semolina dough and Pasta. Cereal Chemistry, 80, 225-231.

This reference was incorporated by suggestion of a reviewer. A complete study of the pasta preparation process and its influence on oxidative properties of dough and pasta was carried out. The importance in our manuscript lies in the contribution with an explanation for the oxidation produced in oil-containing pasta.

Brennan, C.S., Kuri, V., \&Tudorica“, C.M. (2004). Inulin-enriched pasta: effects on textural properties and starch degradation. Food Chemistry, 86, 189-193.

Bustos, M.C., Perez, G.T.,\&León, A.E.(2011). Sensory and nutritional attributes of fibre-enriched pasta. LWT - Food Science and Technology, 44, 1429-1434. doi:10.1016/j.Iwt.2011.02.002 
This is a previous research of our group that study pasta preparation and several pasta characterization methodologies used in the present manuscript.

Codex Alimentarius (2011). Fats, Oils and Related Products, second ed. FAO/WHO Food

Standards Programme, Rome, Italy.

Dick, J.W.,\& Youngs, V.L. (1988). Evaluation of durum wheat semolina and pasta in the United

States. In: Fabriani G. and Lintas C. (eds), Durum Wheat: Chemistry and Technology, St.

Paul, MN: American Association of Cereal Chemistry, 237-248.

Filipović, J., Pezo, L., Filipović, V., Brkljača, J., Krulja, J. (2015). The effects of $\omega-3$ fatty acids and inulin addition to spelt pasta quality.LWT - Food Science and Technology, 63, 43-51.

Gallardo, G., Guida, L., Martinez, V., López, M., Bernhardt, D., Blasco, R., Pedroza-Islas, R., Hermida, L. (2013). Microencapsulation of linseed oil by spray drying for functional. Food Research International, 52, 473-482.

Galli, C.\& Marangoni, F. (2006). N-3 fatty acids in the Mediterranean diet. Prostaglandins Leukot. Essent. Fat. Acids, 75, 129-133.

González, A., Martínez, M.L., Paredes, A.J., León, A.E., \&Ribotta, P.D. (2016). Study of the preparation process and variation of wall components in chia (Salvia hispanica L.) oil microencapsulation. Powder Technology, 301,868-875.

This work is a previous report by the research group. This paper deals with the study of the preparation and characterization of the chia oil microcapsules obtained from freeze-drying methodology and used for the fortification of dry pasta in the present manuscript.

González, A., Martinez, M.L., Leon, A.E., Ribotta, P.D. (2018). Effects on bread and oil quality of the incorporation of microencapsulated chia oil. Journal of the Science of Food and Agriculture, 98, 4903-4910.

Goyal, A., Sharma, V., Sihag, M.K., Singh, A.K., Arora, S., \&Sabikhi, L. (2016). Fortification of dahi (Indian yoghurt) with omega-3 fatty acids using microencapsulated flaxseed oil microcapsules. J Food Sci Technol., 53, 2422-2433.

Hermida, L., \& Gallardo, G.(2015). Food Applications of Microencapsulated Omega-3 Oils. Microencapsulation and Microspheres for Food Applications. Elsevier Inc, 3, 271-300.

This report describes in general terms the application of omega-3 oils, including fortified pasta. It also describes several methodologies used in our research.

Martínez, M.L., Marin, M.A., Gili, R.D., Penci, M.C.,\&Ribotta, P.D.(2017). Effect of defatted almond flour on cooking, chemical and sensorial properties of gluten-free fresh pasta. International Journal of Food Science and Technology, 52, 2148-2155. DOI: 10.1111/ijfs.13493. 
Martínez, M.L., Mattea, M.A., \&Maestri, D.M. (2006). Varietal and crop year effects on lipid composition of walnut (Juglansregia L.) genotypes. J Am Oil Chem Soc., 83, 791-796.

Martínez, M., Marin, M., Salgado,C., Revol, J., Penci, M., \&Ribotta, P.(2012).Chia (Salvia hispanica L.) oil extraction: Study of processing parameters. LWT - FoodScience and Technology, 47, 78-82.

Martínez, M.L. (2010). Doctoral thesis: Utilización de pastas como alimentos funcionales. Departamento de Ciencias Biológicas, Facultad de Ciencias Exactas -Universidad Nacional de La Plata.

Morato, P.N., Rodrigues, J.B., Moura, C.S., Silva, F.G.D., Esmerino, E.A., Cruz, A.G, Bolini, H.M., Amaya-Farfan, J., Barboza Lollo, P.C.(2015). Omega-3 enriched chocolate milk: a functional drink to improve health during exhaustive exercise. J FunctFoods., 14, 676-683.

Rodríguez De Marco, E., Steffolani, M.E., Martínez, M.L., León, A.E. (2018). The use of Nannochloropsis sp. as a source of omega-3 fatty acids in dry pasta: chemical, technological and sensory evaluation. International Journal of Food Science and Technology, 53, 499-507.

Sozer, N. (2009). Rheological properties of rice pasta dough supplemented with proteins and gums. FoodHydrocolloids, 23, 849-855.

Verardo, V., Ferioli, F., Riciputi, Y., Lafelice, G., Marconi, E., \&Caboni, M. F. (2009). Evaluation of lipid oxidation in spaghetti pasta enriched with long chain n-3 polyunsaturated fatty acids under different storage conditions. Food Chemistry, 114, 472-477.

This report is important in our manuscript because an interesting comparison can be carried out between similarly developed foods. In addition, analogous assays were performed, in particular those related to stability tests.

Villeneuve, S., Des Marchais, L., Gauvreau, V., Mercier, S., Do, C.B., Arcand, Y. (2013). Effect of flaxseed processing on engineering properties and fatty acids profiles of pasta. Food and Bioproducts Processing, 91,183-191. 


\section{Figure legends}

Figure 1. Micrographs of scanning electron microscopy (SEM) of the surface of dry and cooked pasta at different magnifications. Dry control pasta at 150x (A), and 300x (B); Dry pasta+oil at 300x $(\mathrm{C})$, and 1000x (D); Dry pasta+MC at 300x (E), and 1000x (F); Cooked control pasta at 300x (G), and 1000x $(\mathrm{H})$; Cooked pasta+oil at 300x (I), and 2000x (J); Cooked pasta+MC at 300x (K), and $2000 x(L)$.

Figure 2. Confocal fluorescence and optical images of dry and cooked samples: Control pasta, Pasta+MC and Pasta+oil.

Figure 3. Evolution of HPV vs storage time for Pasta+MC and Pasta+oil samples packed in modified $\left(\mathrm{N}_{2}\right)$ and unmodified atmosphere (air).

Table 1. Chia oil chemical quality and fatty acid composition.

\section{Parameter}

\begin{tabular}{lc}
\hline Fatty acid profile determination $\mathbf{( g /} \mathbf{~ k g})$ & Value \\
\hline Palmiticacid(16:0) & $70.25 \pm 0.36$ \\
\hline Palmitoleicacid(16:1) & $0.39 \pm 0.00$ \\
\hline Stearicacid (18:0) & $32.7 \pm 0.08$ \\
\hline Oleicacid (18:1) & $74.62 \pm 0.39$ \\
\hline Linoleicacid(18:2) & $197.13 \pm 0.62$ \\
\hline Linolenicacid(18:3) & $607.22 \pm 2.27$ \\
\hline Araquidonicacid (20:0) & $3.78 \pm 0.24$ \\
\hline Eicosanoicacid(20:1) & $13.91 \pm 3.50$ \\
\hline Chemical quality & \\
\hline HPV (meq $\mathrm{O}_{2} / \mathrm{kg}$ oil) & $0.37 \pm 0.03$ \\
\hline Al (mg KOH/g oil) & $1.94 \pm 0.01$ \\
\hline K232 & $1.99 \pm 0.10$
\end{tabular}

This article is protected by copyright. All rights reserved. 
Each value is mean \pm standard deviation $(n=3)$.

HPV (hydroperoxide value), Al (acidity index), K232 (conjugated dienes), K270 (conjugated trienes), OSI (oxidative stability index).

Table 2. Pasta quality parameters of different pasta formulations.

\begin{tabular}{|c|c|c|c|c|}
\hline Sample & OCT (min) & CL \% p/p & WA $\% p / p$ & $\begin{array}{l}\text { SI (g water / g dry } \\
\text { pasta) }\end{array}$ \\
\hline Control Pasta & $6.00 \pm 0.5$ & $5.28 \pm 0.20^{a}$ & $167.58 \pm 8.90^{b}$ & $2.12 \pm 0.10^{b}$ \\
\hline Pasta+MC & $6.00 \pm 0.5$ & $5.46 \pm 0.10^{a}$ & $141.40 \pm 6.20^{a}$ & $1.74 \pm 0.10^{a}$ \\
\hline Pasta+ oil & $6.00 \pm 0.5$ & $5.60 \pm 0.10^{a}$ & $137.15 \pm 5.30^{a}$ & $1.79 \pm 0.10^{a}$ \\
\hline
\end{tabular}

Values followed by a different letter are significantly different $(p<0.05)$; each value is mean \pm standard deviation $(n=3)$.

OCT (Optimal cooking time), CL (cooking loss), WA (water absorption), SI (swelling index).

Table 3. Textural properties of pasta samples before and after cooking.
Sample
Uncooked Pasta
Cooked Pasta

\section{Breaking Force (N) $\quad$ Firmness (N) Adhesiveness (mJ)}

\begin{tabular}{cccc}
\hline Control Pasta & $2.71 \pm 0.23^{\mathrm{a}}$ & $7.65 \pm 0.42^{\mathrm{a}}$ & $0.32 \pm 0.02^{\mathrm{a}}$ \\
\hline Pasta+MC & $1.46 \pm 0.19^{\mathrm{b}}$ & $6.93 \pm 0.35^{\mathrm{a}}$ & $0.28 \pm 0.03^{\mathrm{a}}$ \\
\hline Pasta+oil & $1.17 \pm 0.19^{\mathrm{b}}$ & $7.01 \pm 0.59^{\mathrm{a}}$ & $0.29 \pm 0.04^{\mathrm{a}}$ \\
\hline
\end{tabular}

Mean values \pm SD $(n=6)$. Values in each column followed by identical superscript letter represent no significant differences $(p \geq 0.05)$.

This article is protected by copyright. All rights reserved. 
Table 4. HPV (meq $\mathrm{O}_{2} / \mathrm{kg}$ oil) of the oil contained in pasta formulations before and after cooking.

\begin{tabular}{ccc}
\hline \multirow{2}{*}{ Sample } & \multicolumn{2}{c}{ HPV } \\
\cline { 2 - 3 } & Dry Pasta & Cooked Pasta \\
\hline Pasta+MC & $0.48 \pm 0.10^{\mathrm{aA}}$ & $0.68 \pm 0.02^{\mathrm{bA}}$ \\
\hline Pasta+oil & $1.14 \pm 0.10^{\mathrm{aB}}$ & $3.31 \pm 0.30^{\mathrm{bB}}$ \\
\hline Control oil & & $0.37 \pm 0.03$ \\
\hline
\end{tabular}

HPV (hydroperoxide values)

Mean values $\pm S D(n=4)$. Values in each row for the same pasta formulation followed by identical lower case letters represent no significant differences $(p \geq 0.05)$ among dry and cooked pasta. Values in each column followed by identical capital letter represent no significant differences $(p \geq 0.05)$.

This article is protected by copyright. All rights reserved. 


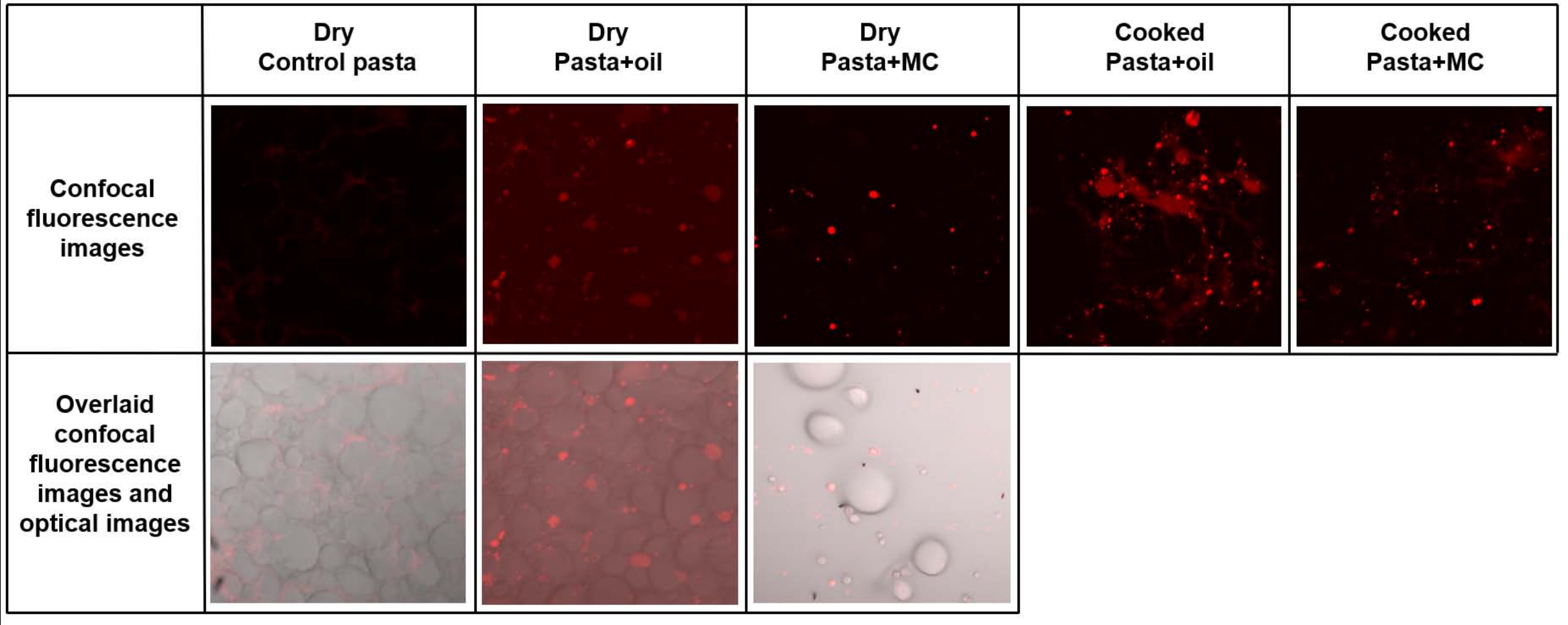




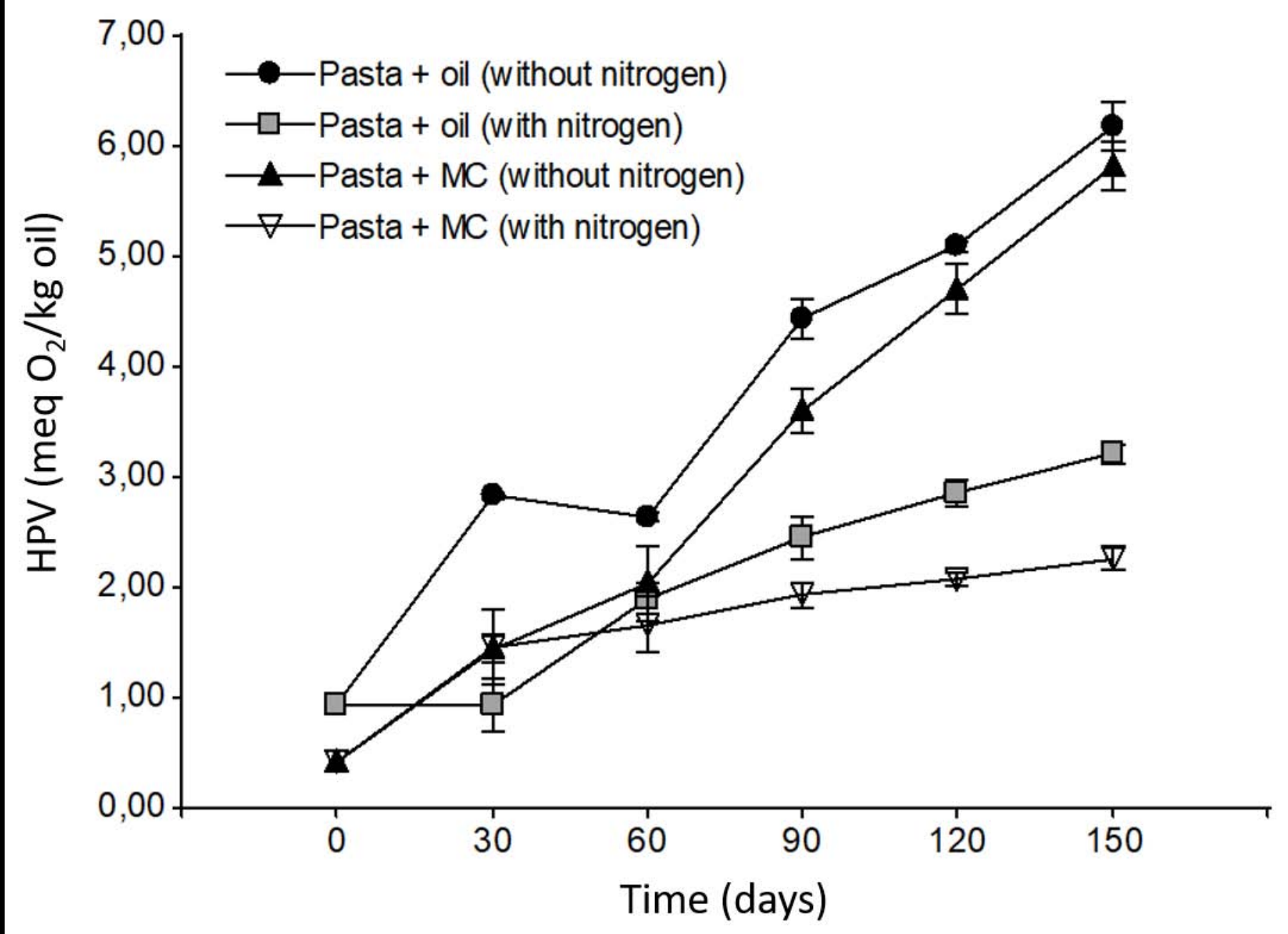

